Document downloaded from:

http://hdl.handle.net/10251/159208

This paper must be cited as:

Floris, I.; Sales Maicas, S.; Calderón García, PA.; Adam, JM. (2019). Measurement uncertainty of multicore optical fiber sensors used to sense curvature and bending direction. Measurement. 132:35-46. https://doi.org/10.1016/j.measurement.2018.09.033

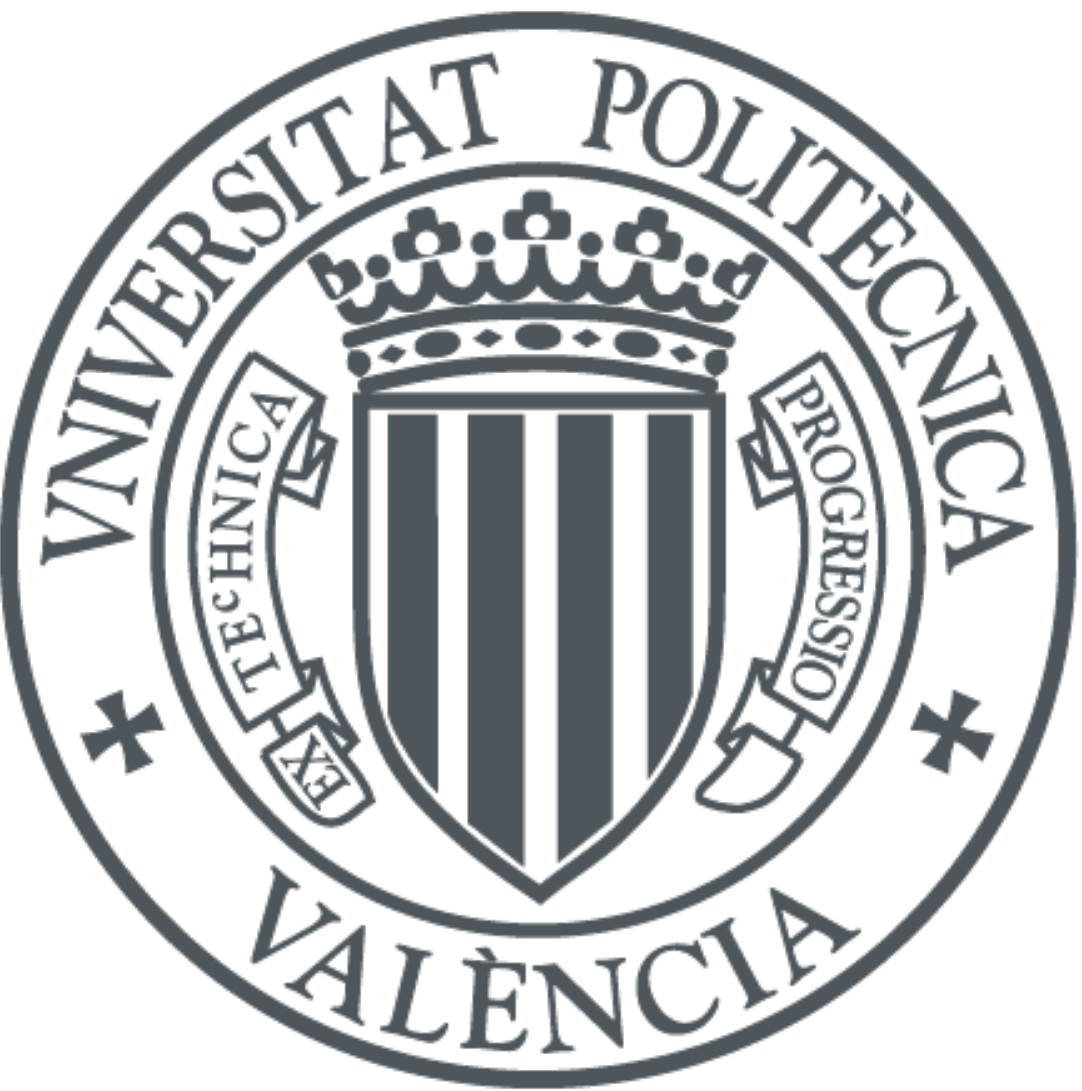

The final publication is available at

https://doi.org/10.1016/j.measurement.2018.09.033

Copyright Elsevier

Additional Information 


\title{
Measurement uncertainty of Multicore Optical Fiber sensors used to sense curvature and bending direction
}

\author{
Ignazio Floris $^{\mathrm{a}, \mathrm{b}}$, Salvador Sales ${ }^{\mathrm{a}}$, Pedro A. Calderón ${ }^{\mathrm{b}}$, Jose M. Adam ${ }^{\mathrm{b} *}$ \\ ${ }^{a}$ ITEAM, Universitat Politècnica de València, Camino de Vera s/n, Valencia, 46022, Spain \\ ${ }^{b}$ ICITECH, Universitat Politècnica de València, Camino de Vera s/n, Valencia, 46022, Spain
}

\begin{abstract}
This paper describes a study of the influence of strain measurement uncertainty on sensing curvature and bending direction, considering one of the most widely used fiber geometries for sensing applications (7-core Multicore Fiber) with different core spacings (distance between outer cores and fiber axis). The Monte Carlo method was proposed to simulate the real measurement process and 33 simulations with $10^{6}$ iterations were performed to determine the laws of propagation of strain measurement uncertainty in calculating curvature and bending direction. The outcomes, which show the strong influence of strain uncertainty and core spacing on the accuracy of Multicore Fiber sensors, can be used to support the design of new sensors or new fiber geometry and to predict their achievable performance.
\end{abstract}

Keywords: Fiber Bragg Grating; Multicore Fiber Optic; Curvature Sensing; Shape Sensing; Monte Carlo Simulation; Error Analysis.

\section{Introduction}

Recent developments in Optical Fiber Sensor (OFS) technology have made these sensors attractive for a number of medical [1], industrial and general engineering applications [2-5]. The reasons for these developments are the unique advantages of OFSs over electrical sensors, including their compactness and light-weight, immunity to electromagnetic interference (EMI), resistance to harsh temperatures, chemicals and radiation and intrinsic safety.

Multicore Fiber (MCF) Sensors for high-precision curvature sensing have many applications in Mechanical, Civil, Aerospace, and Medical Engineering. For example, an ultrasensitive multicore optical fiber-based vector bending sensor has been developed for continuously monitoring the verticality of buildings, towers, bridge piles, and other infrastructures [6], a curvature sensing multicore fiber displacement sensor has been used for tunnel monitoring [7] and a two-axis temperature-insensitive accelerometer has been developed based on an MCF curvature sensor [8].

MCF sensors can also be used to reconstruct the shape of the fiber. Shape sensing can improve the performance of various medical procedures that require high precision in the shape and location of surgical instruments, such as catheters [9]. Multicore optical fiber sensors have been employed to monitor flexible structures, such as aircraft wings, composite wind-turbine blades, suspension bridges, and in high-performance civil, mechanical, and aerospace engineering applications [10].

\footnotetext{
* Corresponding author. Tel.: +34 963877562; fax: +34 963877568.

E-mail address: joadmar@upv.es (Jose M. Adam).
} 
Since shape reconstruction requires extreme precision, high accuracy is needed in curvature and bending direction sensing, which is the basis of the 3D shape reconstruction process.

Fiber Bragg Gratings (FBG) sensors are well established as highly sensitive strain-measuring devices [11]. The magnitude of curvature can be calculated by using a dual-core fiber and comparing the strain detected by pairs of gratings [12-14]. Multi-Core Fiber (MCF), composed of multiple cores with strain sensors (several outer cores displaced from the centerline of the fiber and one core on the axis), can reconstruct the fiber shape. Although three non-aligned cores are sufficient to calculate fiber bending and torsion $[12,15,16]$, further cores can be used to achieve better precision and the fiber shape can be calculated numerically by integrating Frenet-Serret formulas [17].

MCF shape sensing technology has thus become a powerful and reliable instrument for continuous and multidimensional monitoring in engineering applications or ultrasensitive instruments for medical purposes. High accuracy in determining curvature and bending direction is crucial to reliably estimating the shape of the fiber, since these factors are used to calculate the curvature $\kappa(\mathrm{s})$ and torsion $\tau(\mathrm{s})$ functions necessary to reconstruct the fiber shape.

Even though a lot of research has been carried out on MCF sensors, an in-depth study of how certain parameters influence their precision was required to define and extend their limits, improve their sensitivity and identify other possible fields of application.

This paper proposes an algorithm designed to calculate curvature, bending direction and longitudinal deformation, based on the strains detected by the gratings in a 7-core multicore fiber section. With a view to studying the influence of the standard deviation (SD) of the grating strain measurement and the distance between the outer gratings and the fiber axis (core spacing) on curvature and bending direction detection, the measurement process was simulated by the Monte Carlo method and a test to check the statistical significance of the experiment was carried out.

The results of the study successfully identified the propagation laws of strain measurement uncertainty in curvature and bending direction calculation and the influence of core spacing on this phenomenon. The equations, which describe the dependence of strain standard deviation and core spacing on curvature and bending direction precision, are shown in the charts at the end of the paper. These equations can be used to predict the maximum performance (neglecting other error sources) of 7-core MCF sensors when the strain SD and core spacing are known.

\section{Shape sensing background}

\subsection{Multi-core fiber curvature and bending direction measurement}

MCF, with strain sensors in the cores, can be used for shape sensing reconstruction. If the fiber is inside a frictionless constraint and secured only at one end, the natural curve frame will correspond with the material fiber frame along the fiber [18].

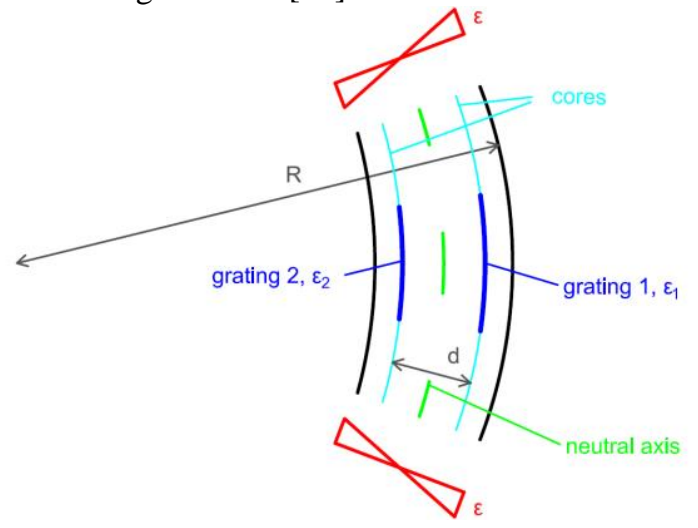


Fig. 1. Multi-core fiber with two gratings for curvature sensing.

Considering a dual-core fiber (gratings at the same temperature) under the Kirchhoff rod assumption, bending induces difference in the strain between the gratings in proportion to the distance from the neural axis, as shown in Fig. 1. By comparing pairs of gratings, it is possible to calculate the magnitude of curvature using Eq. (1):

$\kappa=\Delta \varepsilon / d=\left(\varepsilon_{1}-\varepsilon_{2}\right) / d=1 / R$

where $\kappa$ is the curvature, $\varepsilon_{1}$ and $\varepsilon_{2}$ are the strains detected by the two FBGs, $d$ is the distance between the cores and $R$ is the bending radius [12].

Due to the fiber's short radius, it is reasonable to suppose that the temperature is constant along the section, so that strain differences can be measured without temperature compensation. By using an MCF with at least three non-aligned cores it is possible to calculate the strain along the whole section (the strain surface $\varepsilon(x, y)$ ), with which the curvature and bending direction can be determined in three dimensions $[2,3]$. In doing so, it has been assumed that the errors made in the approximation of the curvature with a constant value are negligible, which is generally true, considering the small length of the gratings.

\subsection{Shape reconstruction}

Assuming that no external twisting forces are induced into the fiber (local twisting is prevented), when the curvature and bending direction are known in several sections, the function of curvature $\kappa(s)$ and torsion $\tau(s)$ can be calculated by curve fitting. With these functions and the tangent, normal and binormal unit vectors, or collectively the Frenet-Serret frame, $\mathrm{T}_{0}, \mathrm{~N}_{0}, \mathrm{~B}_{0}$, at the starting point $\mathrm{r}_{0}$, the shape can be reconstructed through numerical integration of the Frenet-Serret formulas [17], which can be written as:

$$
\left[\begin{array}{l}
\boldsymbol{T}^{\prime} \\
\boldsymbol{N}^{\prime} \\
\boldsymbol{B}^{\prime}
\end{array}\right]=\left[\begin{array}{ccc}
0 & \kappa & 0 \\
-\kappa & 0 & \tau \\
0 & -\tau & 0
\end{array}\right]\left[\begin{array}{l}
\boldsymbol{T} \\
\boldsymbol{N} \\
\boldsymbol{B}
\end{array}\right]
$$

where $\boldsymbol{T}, \boldsymbol{N}$ and $\boldsymbol{B}$ are respectively tangent, normal and binormal unit vectors.

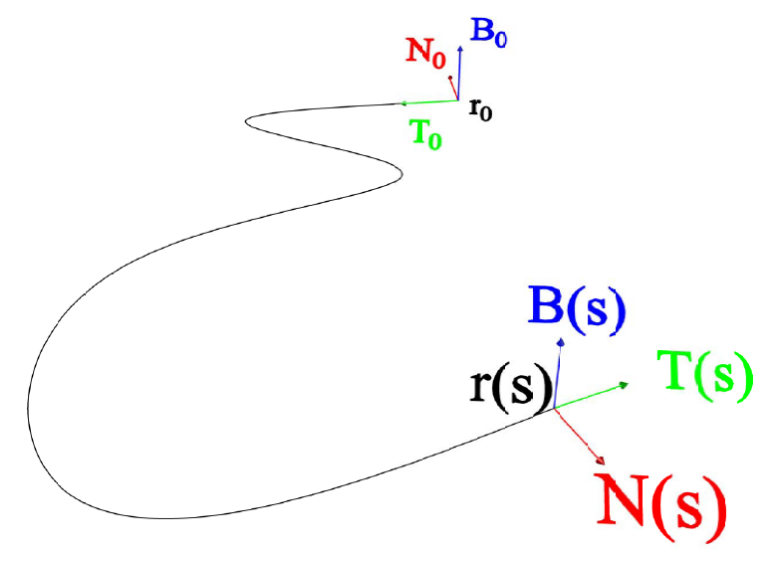

Fig. 2. Space curve and Frenet-Serret frames at the starting point 0 at a generic point $s$. 


\section{Case studies}

\subsection{Fiber geometry}

The fiber geometry and especially the number and position of the cores have a strong influence on the accuracy of the curvature and bending direction obtained. The fibers currently available on the market for 3D shape sensing applications are unfortunately limited in number and are generally the same as those designed for telecommunication applications, such as data center transmission cables, supercomputing and Space Division Multiplexing (SDM) transmission cables [19]. However, their manufacturing costs are prohibitive, considering the limited demand as compared to the telecommunications market. The diameter of such fibers is extremely small (glass diameter of $125 \mu \mathrm{m}$ ) and the distance between the outer cores and the fiber center is commonly between 30 and $50 \mu \mathrm{m}$. This study used one of the most widely used fiber geometries [20-23] for shape sensing applications, the seven-core multicore fiber (see Fig. 3), with 1 central core and 6 outer cores with equal angular spacing of 60 degrees equidistant from the fiber center, including 3 different core spacings: 30,50 and $70 \mu \mathrm{m}$.
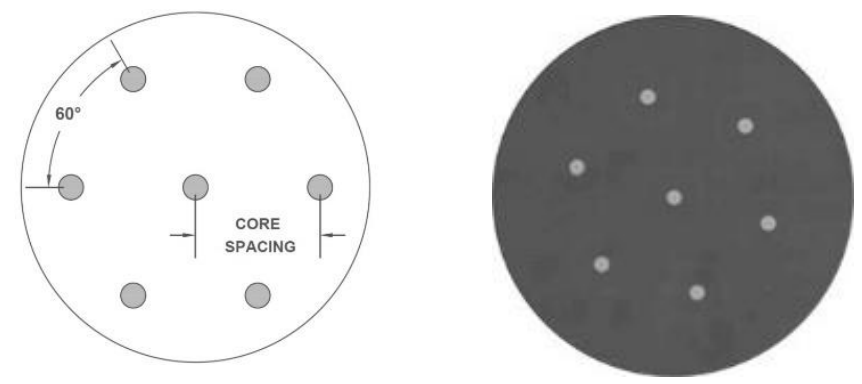

Fig. 3. (a) Seven-core multicore fiber; (b) seven-core multicore fiber produced by FIBERCORE [19]

\subsection{Strain plane calculation from curvature, bending direction and longitudinal strain}

Provided that external twisting forces into the fiber are prevented, under the Euler-Bernoulli hypotheses, when the fiber is subjected to bending the strain surface is a plane. The strain plane $\varepsilon(x, y)$, at the considered section, can be calculated if the curvature, bending direction and 
longitudinal fiber strain are known, after defining a local Cartesian Coordinate System $(x, y)$
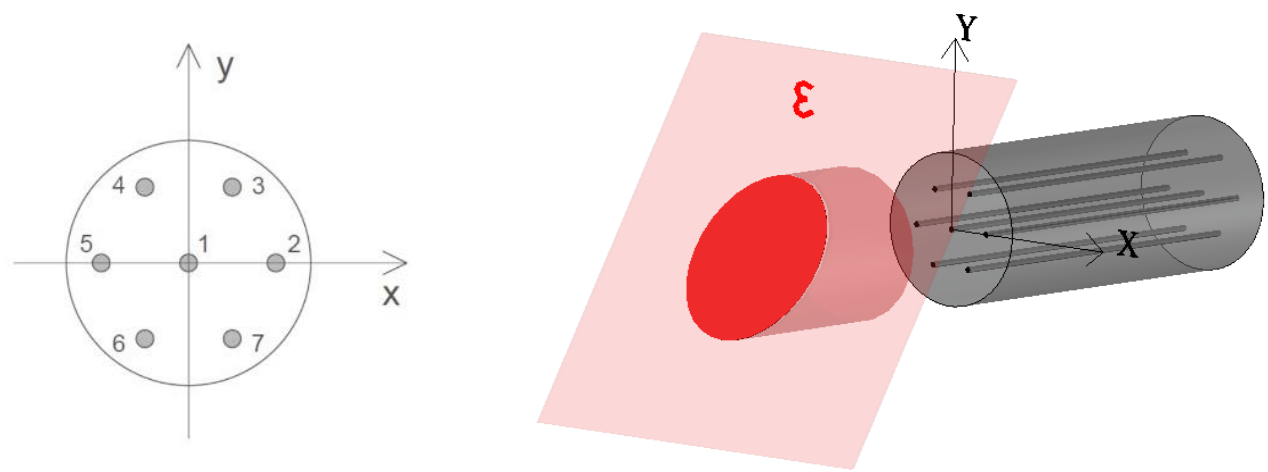

centered on the mid-section, as shown in Fig. 4.

Fig. 4. (a) Cartesian Coordinate System $(x, y)$ in a seven-core multicore fiber; (b) 3D distribution of the strain under a fiber bending and traction.

After calculating the strain plane equation, the strain of all the cores can be determined. These are the exact strain values, which would be detected by the gratings without measurement uncertainly in strain detection.

\subsection{Monte Carlo simulation}

The Monte Carlo method (MCM) was developed as an experimental probabilistic method of solving difficult linear and nonlinear deterministic problems [24-27] and is now recognized as a powerful instrument for solving many different scientific and technical problems. Since modern computers can easily simulate large numbers of experimental trials that have random outcomes, MCM, a large class of computational algorithms, were developed to confront processes that could not be easily predicted with the aim of obtaining numerical results and modeling the probability of different outcomes that rely on repeated random sampling.

The MCM can be used to determine the probability distribution for an output quantity from the probability distributions assigned to the input quantities on which the output quantity depends in order to define the law of propagation $[28,29]$. Before simulation, a specification of the input probability distribution needs to be defined to perform the random sampling. Although analytical methods are ideal because they do not require an approximation, they are applicable in simple cases only and in practice the propagation of distributions cannot be implemented without making approximations in complex cases [29].

When applied to uncertainty estimation, the MCM simulates a real measurement process, which is probabilistic in nature, by randomly sampling the uncertainty of the parameters, generating thousands or even hundreds of thousands of measurements and consequent outcomes and creating artificial features.

In this study the MCM was used to simulate the errors in strain measurement assuming that the errors detected in different gratings were independent, uncorrelated and followed a standard normal distribution (input Gaussian probability distribution) with a certain standard deviation.

The errors in strain measurement represent the errors of the strain measurement process, which depend on interrogation process: resolution of the interrogation system, technique used to track the peaks and determine the shift of wavelength, conversion of shift of wavelength in strain, and environmental conditions: temperature, vibrations, etc. 
For each trial the errors in the strain measurement were then simulated and added to the exact strain value in all the cores.

\subsubsection{Case 1: Uncertainty in curvature calculation}

Fifteen simulations were performed to study the measurement uncertainty in curvature determination considering: longitudinal strain equal to $0 \mu \varepsilon$; bending direction corresponding to axis $\mathrm{x}$; three different values of core spacing, including 70,50 and $30 \mu \mathrm{m}$; five different values of standard deviation in strain measurement, including $5,2.5,1,0.5$ and $0.2 \mu \varepsilon$. The values of strain measurement were chosen considering that the resolution of commercial interrogation system is nowadays around $1 \mu \varepsilon$ and it will decrease in the future so that a reasonable value of strain measurement SD is between 5 and $0.2 \mu \varepsilon$. Since the curvatures sensed have no influence on curvature distribution, their values were calculated so that the maximum strain value in the section, without measurement errors, was equal to $1000 \mu \varepsilon$, as shown in Table 1.

Table 1. Simulations for identification of uncertainty in curvature calculation.

\begin{tabular}{|c|c|c|c|c|c|}
\hline Simulation $N^{\mathbf{0}}$ & $\begin{array}{c}\text { Longitudinal } \\
\text { Strain }[\mu \varepsilon]\end{array}$ & $\begin{array}{c}\text { Angle between } \\
\text { Bending Direction } \\
\text { and axis } x[\mathrm{rad}]\end{array}$ & Curvature $\left[\mathrm{m}^{-1}\right]$ & $\begin{array}{c}\text { Standard } \\
\text { Core spacing }[\mu \mathrm{m}]\end{array}$ & $\begin{array}{c}\text { Deviation in Strain } \\
\text { Measurement }[\mu \varepsilon]\end{array}$ \\
\hline 1 & 0.00 & 0.00 & 14.286 & 70.00 & 5.00 \\
2 & 0.00 & 0.00 & 14.286 & 70.00 & 2.50 \\
3 & 0.00 & 0.00 & 14.286 & 70.00 & 1.00 \\
4 & 0.00 & 0.00 & 14.286 & 70.00 & 0.50 \\
5 & 0.00 & 0.00 & 14.286 & 50.00 & 0.20 \\
6 & 0.00 & 0.00 & 20.000 & 50.00 & 5.00 \\
7 & 0.00 & 0.00 & 20.000 & 50.00 & 2.50 \\
8 & 0.00 & 0.00 & 20.000 & 50.00 & 1.00 \\
10 & 0.00 & 0.00 & 20.000 & 50.00 & 0.50 \\
11 & 0.00 & 0.00 & 20.000 & 30.00 & 0.20 \\
13 & 0.00 & 0.00 & 33.333 & 30.00 & 5.00 \\
15 & 0.00 & 0.00 & 33.333 & 30.00 & 2.50 \\
\end{tabular}

\subsubsection{Case 2: Uncertainty in bending direction calculation}

Eighteen simulations were performed with a view to analyzing the measurement uncertainty in determining the angle between bending direction and axis $\mathrm{x}$, considering: longitudinal strain equal to $0 \mu \varepsilon$; bending direction corresponding to axis $\mathrm{x}$; three different values of core spacing, including 70,50 and $30 \mu \mathrm{m}$; three different values of standard deviation in strain measurement, including 5, 1 and $0.2 \mu \varepsilon$; two different values of curvature for each core spacing value, as shown in Table 2 .

Fig. 5 shows an example of the Gaussian error distributions in the cores of the first simulation of the second case study. The exact values of strain in the core, not affected by measurement errors, are shown in Table 3.

Table 2. Simulations for identification of uncertainty in bending direction calculation. 


\begin{tabular}{|c|c|c|c|c|c|}
\hline $\begin{array}{l}\text { Simulation } \\
\text { number }\end{array}$ & $\begin{array}{c}\text { Longitudinal } \\
\text { Strain }[\mu \varepsilon]\end{array}$ & $\begin{array}{l}\text { Angle between } \\
\text { Bending Direction } \\
\text { and axis x [rad] }\end{array}$ & Curvature $\left[\mathrm{m}^{-1}\right]$ & Core spacing $[\mu \mathrm{m}]$ & $\begin{array}{c}\text { Standard } \\
\text { Deviation in Strain } \\
\text { Measurement }[\mu \varepsilon]\end{array}$ \\
\hline 1 & 0.00 & 0.00 & 0.071 & 70.00 & 5.00 \\
\hline 2 & 0.00 & 0.00 & 0.214 & 70.00 & 5.00 \\
\hline 3 & 0.00 & 0.00 & 0.071 & 70.00 & 1.00 \\
\hline 4 & 0.00 & 0.00 & 0.214 & 70.00 & 1.00 \\
\hline 5 & 0.00 & 0.00 & 0.071 & 70.00 & 0.20 \\
\hline 6 & 0.00 & 0.00 & 0.214 & 70.00 & 0.20 \\
\hline 7 & 0.00 & 0.00 & 0.200 & 50.00 & 5.00 \\
\hline 8 & 0.00 & 0.00 & 0.400 & 50.00 & 5.00 \\
\hline 9 & 0.00 & 0.00 & 0.200 & 50.00 & 1.00 \\
\hline 10 & 0.00 & 0.00 & 0.400 & 50.00 & 1.00 \\
\hline 11 & 0.00 & 0.00 & 0.200 & 50.00 & 0.20 \\
\hline 12 & 0.00 & 0.00 & 0.400 & 50.00 & 0.20 \\
\hline 13 & 0.00 & 0.00 & 0.500 & 30.00 & 5.00 \\
\hline 14 & 0.00 & 0.00 & 0.833 & 30.00 & 5.00 \\
\hline 15 & 0.00 & 0.00 & 0.500 & 30.00 & 1.00 \\
\hline 16 & 0.00 & 0.00 & 0.833 & 30.00 & 1.00 \\
\hline 17 & 0.00 & 0.00 & 0.500 & 30.00 & 0.20 \\
\hline 18 & 0.00 & 0.00 & 0.833 & 30.00 & 0.20 \\
\hline
\end{tabular}

Table 3. Strain values in the seven cores without measurement errors in the first simulation of the 2 nd case study.

\begin{tabular}{|c|c|c|c|c|c|c|}
\hline \multicolumn{2}{|c|}{$\begin{array}{c}\text { Curvature }\left[\mathrm{m}^{-1}\right] \\
0.71\end{array}$} & \multicolumn{3}{|c|}{$\begin{array}{c}\text { Core spacing }[\mu \mathrm{m}] \\
70.00\end{array}$} & \multicolumn{2}{|c|}{$\begin{array}{c}\text { Standard Deviation in Strain } \\
\text { Measurement }[\mu \varepsilon] \\
5.00\end{array}$} \\
\hline $\begin{array}{c}\varepsilon_{1} \\
0.00\end{array}$ & $\begin{array}{c}\varepsilon_{2} \\
5.00\end{array}$ & $\begin{array}{c}\varepsilon_{3} \\
2.50\end{array}$ & $\begin{array}{c}\varepsilon_{4} \\
-2.50\end{array}$ & $\begin{array}{c}\varepsilon_{5} \\
-5.00\end{array}$ & $\begin{array}{c}\varepsilon_{6} \\
-2.50\end{array}$ & $\begin{array}{c}\varepsilon_{7} \\
2.50\end{array}$ \\
\hline
\end{tabular}



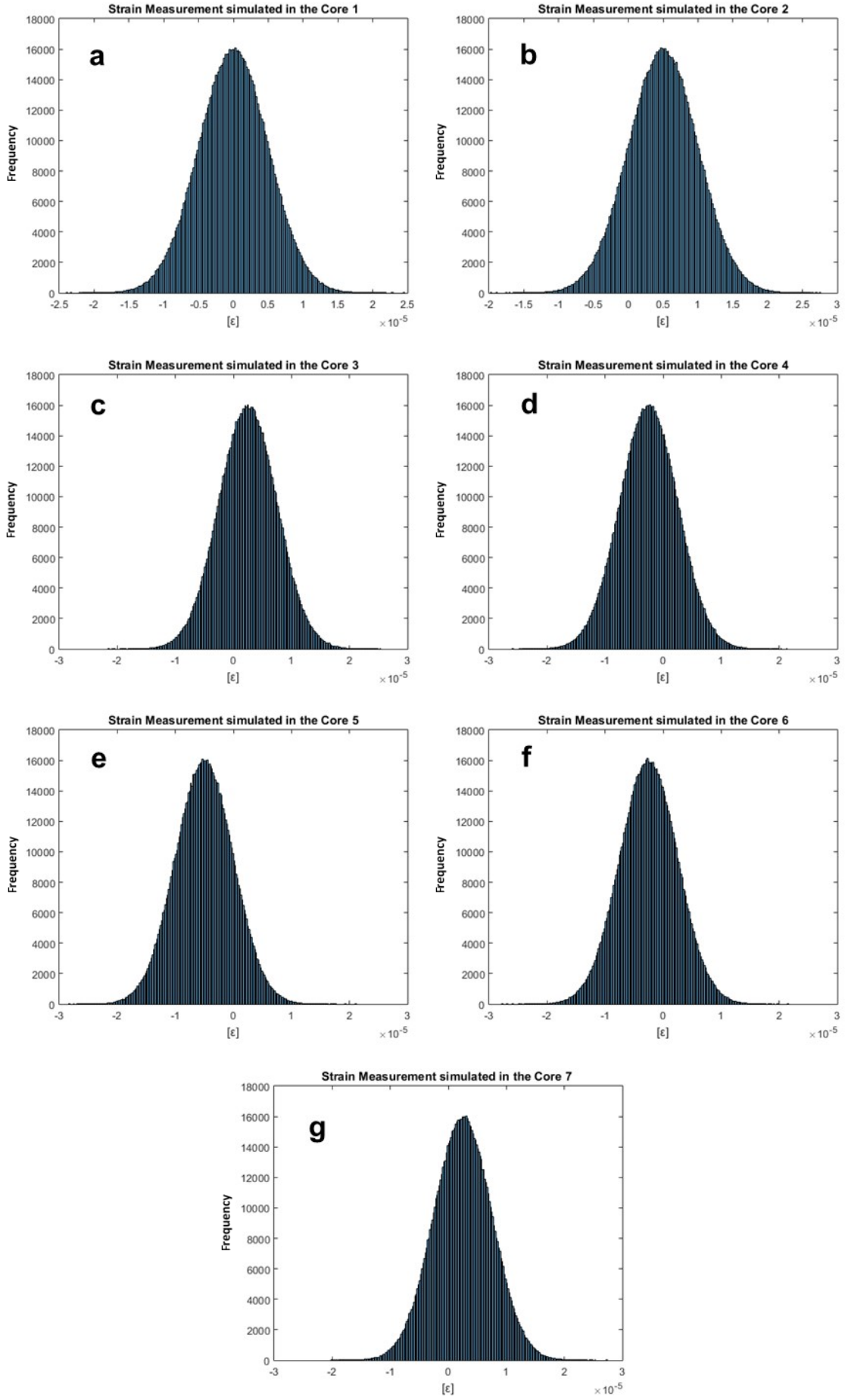

Fig. 5. Strain measurement simulated in the first simulation of the identification of uncertainty in bending direction in core 1 (a); core 2 (b); core 3 (c); core 4 (d); core 5 (e); core 6 (f); core 7 (g). 


\subsection{Calculating curvature, bending direction and longitudinal strain}

Considering the error-affected strain value generated by MCM, the curvature and bending direction were calculated in each trial to determine the relation between core spacing and the standard deviations of strain measurement and curvature and bend direction angle.

The strain surface was first calculated considering the strain values of the 7 cores through a Multivariate Linear Regression analysis. The curvature was then calculated by Eqs. (3) and (4) with the known strain plane equation $\varepsilon(x, y)$ :

$\kappa=\sqrt{\kappa_{X}^{2}+\kappa_{Y}^{2}}$

$\kappa_{x}=\Delta \varepsilon_{x} / 2 s ; \kappa_{y}=\Delta \varepsilon_{y} / 2 s$

where $\kappa$ is the curvature, $\kappa_{x}$ and $\kappa_{y}$ are, respectively, the components of curvature along the axis $x$ and $y, \Delta \varepsilon_{x}$ and $\Delta \varepsilon_{y}$ are the variations in strain along the axis $x$ and $y$ respectively and $s$ is the spacing core, the distance between the fiber center and the outer core centers. The bending direction, or direction of maximum curvature, and longitudinal strain (average strain in the section) were then calculated.

\subsection{Stopping Rules}

The effectiveness of the MCM depends on the number of iterations. Unfortunately, the appropriate number of iterations required for reliable results cannot be estimated theoretically [30]. By increasing the number of trials, the statistics will stabilize at a constant value and the simulation should then be stopped. However, a number between $10^{5}$ and $10^{6}$ iterations seems to be sufficient in most cases [31] and a trial value of $10^{6} \mathrm{can}$ often be expected to deliver a $95 \%$ coverage interval for the output quantity, such that this length is correct to one or two significant decimal places [29].

Each simulation in the study was carried out with $10^{6}$ iterations. For each simulation, the total dataset consisted of 5 subdatasets with $2 \cdot 10^{5}$ trials each. To ensure that the simulations were statistically significant, the values obtained with the five subdatasets were compared with the value given by the total dataset. The results of the comparison are given in Section 6.

\section{Multi-step procedure for curvature and bending direction calculation}

An algorithm was developed in MATLAB ${ }^{\circledR}$ code [32] to generate the error distribution by the Monte Carlo method and compute the resulting distribution of longitudinal deformation, curvature and bending direction. The procedure can be summarized as follows:

- Step 1. Strain calculation in all the cores, given the fiber geometry, longitudinal deformation, curvature and bending direction, as shown at point 3.2.

- Step 2. Simulation of strain Gaussian distribution in all the cores, given the standard deviation in strain detection, as shown at point 3.3.

- Step 3. Calculation of longitudinal deformation, curvature and bending direction angle distribution through Multivariate Linear Regression analysis, as explained at point 3.4.

- Step 4. Tests of Statistical Significance.

\section{Results and comments}

This section deals with the outcome of the experiments for curvature and bending direction calculation. 


\subsection{Longitudinal strain distribution}

The longitudinal strain of the fiber distribution (supposed equal to zero without measurements errors) was calculated for each simulation. Fig. 6 shows an example of the longitudinal strain distribution (first simulation of the second case study), which is clearly Gaussian. The SD of the distribution remained below a value of $2 \cdot 10^{-6} \mu \varepsilon$ during the entire simulation.

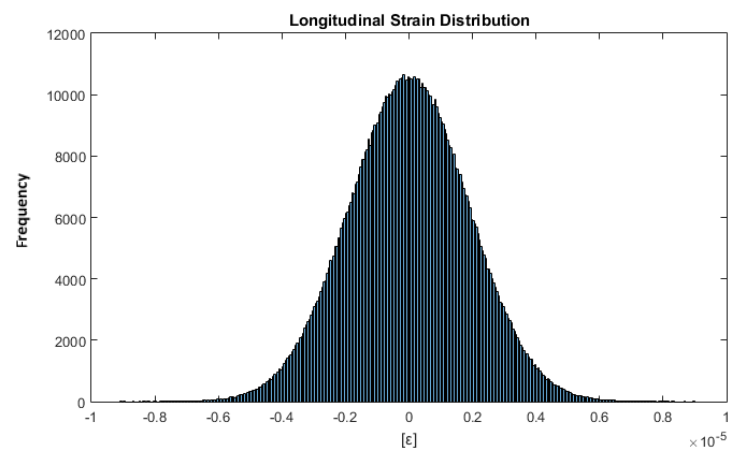

Fig. 6. Longitudinal fiber strain measurement simulated in the 7 core in the first simulation of the second case study.

\subsection{Case 1: Curvature calculation}

Fifteen simulations were carried out to evaluate the effect of the errors on strain measurement and the variation of core spacing in curvature sensing, as explained at point 3.3.1, including different $\mathrm{SD}$ values in strain measurement and core spacing. Since the curvature was calculated as the vector addition of the two curvature components along the $\mathrm{x}$ and $\mathrm{y}$ axes by Eq. (2), curvature is a positivedefinite function, so that in the neighborhood of the origin the shape of the distribution is distorted, as can be seen in Fig. 7. To avoid this inconvenience, the distributions of the curvature components along the $\mathrm{x}$ and $\mathrm{y}$ axes may be studied, as shown in Fig. 8. In view of this, in the first case study only considerable curvatures far removed from the value of zero were analyzed. Fig. 9 shows, as example, the distribution of the curvature in the first simulation of the first case of study. The curvature distribution is still Gaussian.

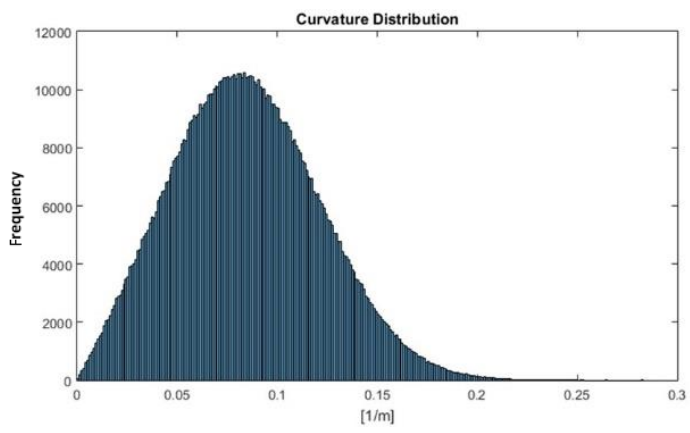

Fig. 7. Curvature distribution in first simulation for the identification of uncertainty in bending direction calculation. 

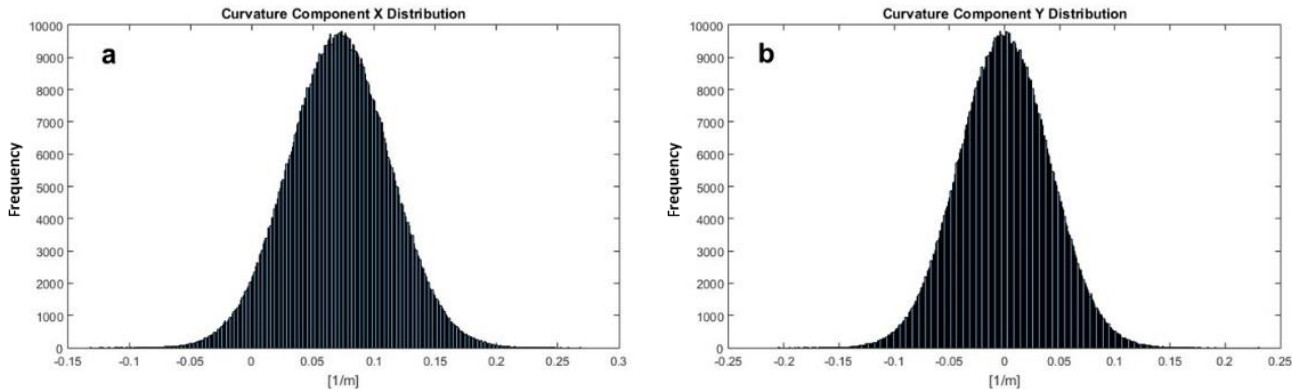

Fig. 8. (a) Distribution of curvature along axis $x$ in first simulation for the identification of uncertainty in bending direction calculation; (b) distribution of curvature along axis y in first simulation for the identification of uncertainty in bending direction calculation.

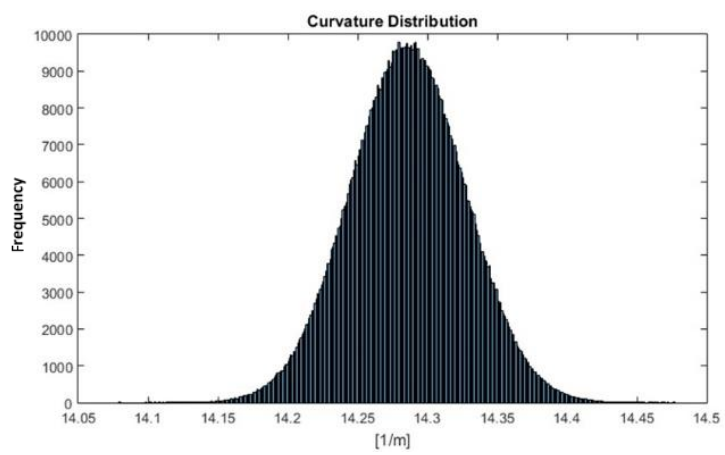

Fig. 9. Curvature distribution in first simulation for the identification of uncertainty in curvature calculation.

The outcomes of the first experiment are shown in Table 4. Three different core spacing values and five different SD values were considered in strain measurement. The curvature values were calculated so that the maximum strain value in the section, without measurement errors, was equal to $1000 \mu \varepsilon$. This was possible since the curvature sensed had no influence on the curvature distribution. Curvature distribution was calculated for each simulation considering its SD.

Fig. 9 shows the variation of the curvature and strain standard deviations at a constant core spacing value. As can be seen, curvature SD varies linearly with strain SD. The regression line equations and coefficients of determination (R2) are shown in the figure. 
Table 4. Curvature standard deviation results.

\begin{tabular}{c|c|c|c|c}
\hline Simulation $N^{\mathbf{0}}$ & Curvature $\left[\mathrm{m}^{-1}\right]$ & Core spacing $[\mu \mathrm{m}]$ & $\begin{array}{c}\text { SD in Strain } \\
\text { Measurement }[\mu \varepsilon]\end{array}$ & Curvature SD $\left[\mathrm{m}^{-1}\right]$ \\
\hline 1 & 14.2857 & 70.00 & 5.00 & 0.0412 \\
2 & 14.2857 & 70.00 & 2.50 & 0.0206 \\
3 & 14.2857 & 70.00 & 1.00 & 0.0083 \\
4 & 14.2857 & 70.00 & 0.50 & 0.0041 \\
5 & 14.2857 & 70.00 & 0.20 & 0.0016 \\
6 & 20.0000 & 50.00 & 5.00 & 0.0578 \\
7 & 20.0000 & 50.00 & 2.50 & 0.0289 \\
8 & 20.0000 & 50.00 & 1.00 & 0.0115 \\
9 & 20.0000 & 50.00 & 0.50 & 0.0058 \\
10 & 20.0000 & 50.00 & 0.20 & 0.0023 \\
11 & 33.3333 & 30.00 & 5.00 & 0.0963 \\
12 & 33.3333 & 30.00 & 2.50 & 0.0481 \\
13 & 33.3333 & 30.00 & 1.00 & 0.0192 \\
14 & 33.3333 & 30.00 & 0.50 & 0.0096 \\
15 & 33.3333 & 30.00 & 0.20 & 0.0038 \\
\hline
\end{tabular}

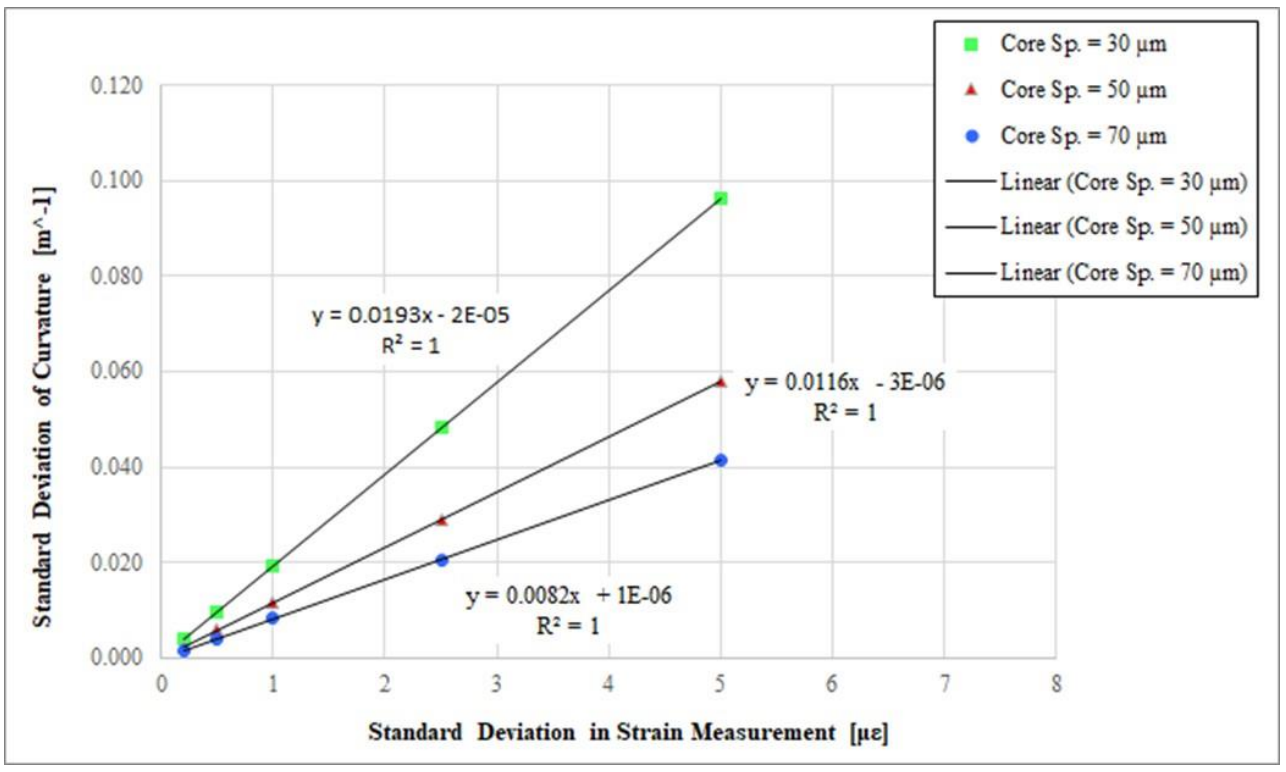

Fig. 10. Curvature SD results for each strain SD point at constant core spacing values.

The curvature SD variation with constant core spacing at a constant SD deviation value is shown in Fig. 11. In this case, the relationships are not linear and were approximated by a quadratic polynomial, whose equations are shown in the figure. 


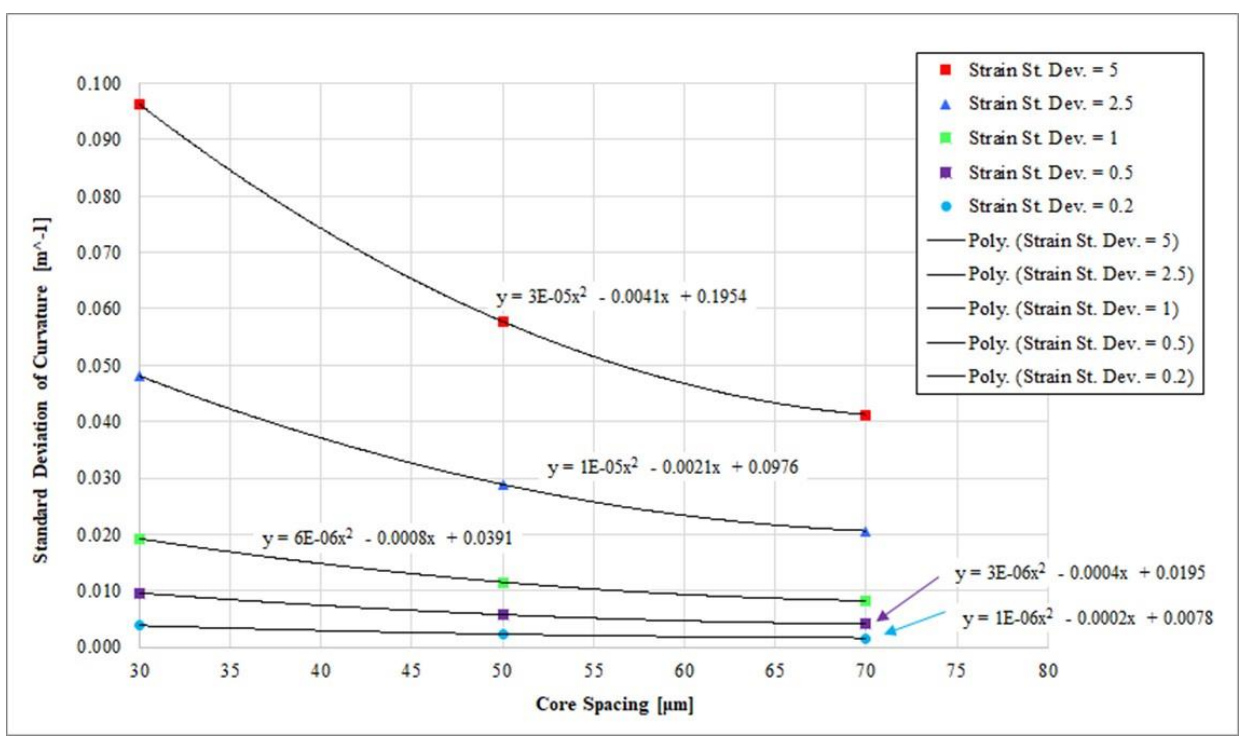

Fig. 11. Curvature SD results for each core spacing point at constant values of strain SD.

As explained in Section 4.5, MCM requires a stopping rule that determines the length of the sample records (number of samples in the simulation). Since the appropriate number of iterations cannot be estimated theoretically [23], we opted for $10^{6}$, which seems to be sufficient in most cases $[18,24]$. The correctness of this assumption was later verified. For each simulation, the curvature distribution of the total dataset, consisting of 5 subdatasets with $2 \cdot 10^{5}$ trials each, was determined and its standard deviation was compared with the standard deviation of the distribution of the subdatasets. The results of the comparison are shown in Table 5.

The percentage error of the subdatasets' SD was then compared with that of the total dataset SD for each simulation by Eq. (5):

$E p=\left[\left(s^{T}-s^{S}\right) / s^{T}\right] 100$

where $E p$ is the percentage error, $s^{T}$ is the standard deviation of the total dataset and $s^{S}$ is the standard deviation of the subdataset. The percentage errors of all the simulations in the first case study are shown in Table 6 . The highest percentage error obtained was 0.340 , indicating that the simulation can be considered statistically significant. 
Table 5. Curvature SD results; comparison of subdatasets and total datasets.

\begin{tabular}{c|c|c|c|c|c|c}
\hline $\begin{array}{c}\text { Simulation } \\
\text { number }\end{array}$ & $\begin{array}{c}\text { Curvature St. } \\
\text { Dev. } 1^{\circ} \\
\text { subdataset }\end{array}$ & $\begin{array}{c}\text { Curvature St. } \\
\text { Dev. } 2^{\text {o }} \\
\text { subdataset }\end{array}$ & $\begin{array}{c}\text { Curvature St. } \\
\text { Dev. } 3^{\text {o }} \\
\text { subdataset }\end{array}$ & $\begin{array}{c}\text { Curvature St. } \\
\text { Dev. } 4^{\text {o }} \\
\text { subdataset }\end{array}$ & $\begin{array}{c}\text { Curvature St. } \\
\text { Dev. } 5^{\text {o }} \\
\text { subdataset }\end{array}$ & $\begin{array}{c}\text { Curvature St. } \\
\text { Dev. Total } \\
\text { dataset }\end{array}$ \\
\hline 1 & 0.041250 & 0.041247 & 0.041209 & 0.041243 & 0.041257 & 0.041241 \\
2 & 0.020658 & 0.020605 & 0.020615 & 0.020704 & 0.020586 & 0.020633 \\
3 & 0.008245 & 0.008251 & 0.008248 & 0.008258 & 0.008269 & 0.008254 \\
4 & 0.004125 & 0.004113 & 0.004120 & 0.004117 & 0.004121 & 0.004119 \\
5 & 0.001654 & 0.001647 & 0.001644 & 0.001651 & 0.001649 & 0.001649 \\
6 & 0.057681 & 0.057791 & 0.057660 & 0.057810 & 0.057844 & 0.057757 \\
7 & 0.028966 & 0.028846 & 0.028876 & 0.028797 & 0.028860 & 0.028869 \\
8 & 0.011551 & 0.011525 & 0.011510 & 0.011553 & 0.011578 & 0.011543 \\
9 & 0.005769 & 0.005768 & 0.005782 & 0.005777 & 0.005787 & 0.005777 \\
10 & 0.002312 & 0.002306 & 0.002310 & 0.002311 & 0.002310 & 0.002310 \\
11 & 0.096011 & 0.096468 & 0.096271 & 0.096349 & 0.096428 & 0.096305 \\
12 & 0.048108 & 0.048173 & 0.048150 & 0.048026 & 0.048092 & 0.048110 \\
13 & 0.019209 & 0.019247 & 0.019250 & 0.019275 & 0.019251 & 0.019247 \\
14 & 0.009626 & 0.009604 & 0.009620 & 0.009620 & 0.009631 & 0.009620 \\
15 & 0.003844 & 0.003851 & 0.003842 & 0.003846 & 0.003842 & 0.003845 \\
\hline
\end{tabular}

Table 6. Curvature standard deviation results; percentage errors.

\begin{tabular}{c|c|c|c|c|c}
\hline $\begin{array}{c}\text { Simulation } \\
\text { number }\end{array}$ & $\begin{array}{c}\text { Percentage } \\
\text { Error } 1^{\mathbf{0}} \text { dataset }\end{array}$ & $\begin{array}{c}\text { Percentage } \\
\text { Error } 2^{\mathbf{0}} \text { dataset }\end{array}$ & $\begin{array}{c}\text { Percentage } \\
\text { Error } 3^{\mathbf{0}} \text { dataset }\end{array}$ & $\begin{array}{c}\text { Percentage } \\
\text { Error } 4^{\mathbf{0}} \text { dataset }\end{array}$ & $\begin{array}{c}\text { Percentage } \\
\text { Error 5 dataset }\end{array}$ \\
\hline 1 & -0.022 & -0.015 & 0.078 & -0.005 & -0.037 \\
2 & -0.117 & 0.137 & 0.091 & -0.340 & 0.230 \\
3 & 0.107 & 0.038 & 0.076 & -0.044 & -0.177 \\
4 & -0.135 & 0.154 & -0.015 & 0.041 & -0.044 \\
5 & -0.277 & 0.114 & 0.315 & -0.136 & -0.015 \\
6 & 0.132 & -0.058 & 0.168 & -0.091 & -0.150 \\
7 & -0.336 & 0.079 & -0.025 & 0.251 & 0.033 \\
8 & -0.065 & 0.161 & 0.288 & -0.082 & -0.299 \\
9 & 0.129 & 0.151 & -0.093 & -0.009 & -0.177 \\
10 & -0.088 & 0.166 & 0.013 & -0.065 & -0.025 \\
11 & 0.306 & -0.169 & 0.036 & -0.045 & -0.128 \\
12 & 0.003 & -0.130 & -0.083 & 0.174 & 0.038 \\
13 & 0.196 & -0.003 & -0.018 & -0.148 & -0.025 \\
14 & -0.061 & 0.166 & 0.004 & 0.004 & -0.114 \\
15 & 0.022 & -0.158 & 0.086 & -0.025 & 0.075 \\
\hline
\end{tabular}

\subsection{Case 2: Calculating bending direction angle}

The second case study involved the impact of the strain measurement SD and core spacing on the bending direction calculations. The bending direction and the angle between the bending 
direction and the $\mathrm{x}$ axis (null without measurement errors) were estimated for each trial. The distribution of the bending direction angle was then considered for each simulation. Once again, as in the strain measurement, the distribution of the resulting quantity was Gaussian, as can be seen from Fig. 12. The bending direction angle distribution was studied in the interval from $-\pi$ to $+\pi$ in order to identify all the possible configurations of the bending axis.

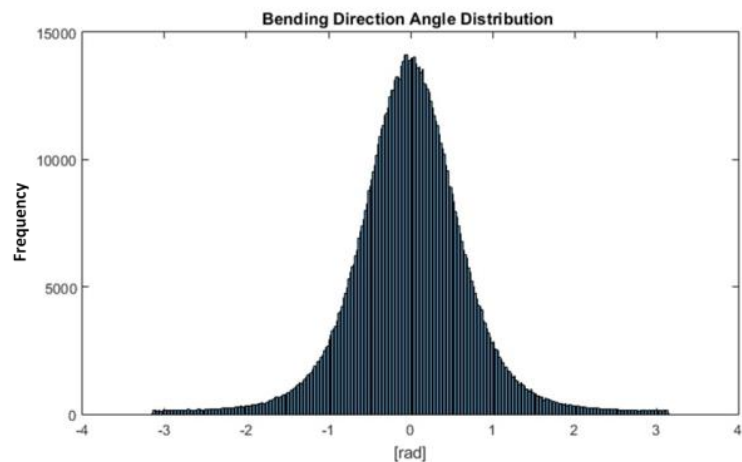

Fig. 12. Bending direction angle distribution of the first simulation to identify uncertainty in bending direction calculations.

The SD associated with each simulation are listed in Table 7. Three different values of core spacing and three different values of standard deviation in strain measurement were considered. Since the standard deviation of the bending direction angle distribution was found to be closely dependent on the curvature sensed in the preliminary analysis, two different curvature values were considered for each strain SD and core spacing value.

Table 7. Bending direction angle standard deviation results.

\begin{tabular}{c|c|c|c|c}
\hline $\begin{array}{c}\text { Simulation } \\
\text { number }\end{array}$ & Curvature $\left[\mathrm{m}^{-1}\right]$ & $\begin{array}{c}\text { Core spacing } \\
{[\mu \mathrm{m}]}\end{array}$ & $\begin{array}{c}\text { St. Dev. in Strain } \\
\text { Meas. }[\mu \varepsilon]\end{array}$ & $\begin{array}{c}\text { Bend. Dir. Angle } \\
\text { St. Dev. }\end{array}$ \\
\hline 1 & 0.0714 & 70.00 & 5.00 & 0.7142 \\
2 & 0.2143 & 70.00 & 5.00 & 0.1964 \\
3 & 0.0714 & 70.00 & 1.00 & 0.1164 \\
4 & 0.2143 & 70.00 & 1.00 & 0.0385 \\
5 & 0.0714 & 70.00 & 0.20 & 0.0231 \\
6 & 0.2143 & 70.00 & 0.20 & 0.0077 \\
7 & 0.2000 & 50.00 & 5.00 & 0.3051 \\
8 & 0.4000 & 50.00 & 5.00 & 0.1459 \\
9 & 0.2000 & 50.00 & 1.00 & 0.0579 \\
10 & 0.4000 & 50.00 & 1.00 & 0.0288 \\
11 & 0.2000 & 50.00 & 0.20 & 0.0115 \\
12 & 0.4000 & 50.00 & 0.20 & 0.0058 \\
13 & 0.5000 & 30.00 & 5.00 & 0.1965 \\
14 & 0.8333 & 30.00 & 5.00 & 0.1161 \\
15 & 0.5000 & 30.00 & 1.00 & 0.0385 \\
16 & 0.8333 & 30.00 & 1.00 & 0.0231 \\
17 & 0.5000 & 30.00 & 0.20 & 0.0077 \\
18 & 0.8333 & 30.00 & 0.20 & 0.0046 \\
\hline
\end{tabular}


Fig. 13 shows the bending direction angle SD variation with strain SD at a constant value of core spacing and curvature. The bending direction angle SD varies linearly with the strain SD. The regression line equations and coefficients of determination $\left(\mathrm{R}^{2}\right)$ are included in the figure. As can be seen, the data points with a curvature of $0.214 \mathrm{~m}^{-1}$ and core spacing $70 \mu \mathrm{m}$ coincide with those associated with curvature values of $0.500 \mathrm{~m}^{-1}$ and core spacing of $30 \mu \mathrm{m}$, since the product of curvature and core spacing is the same in both cases.

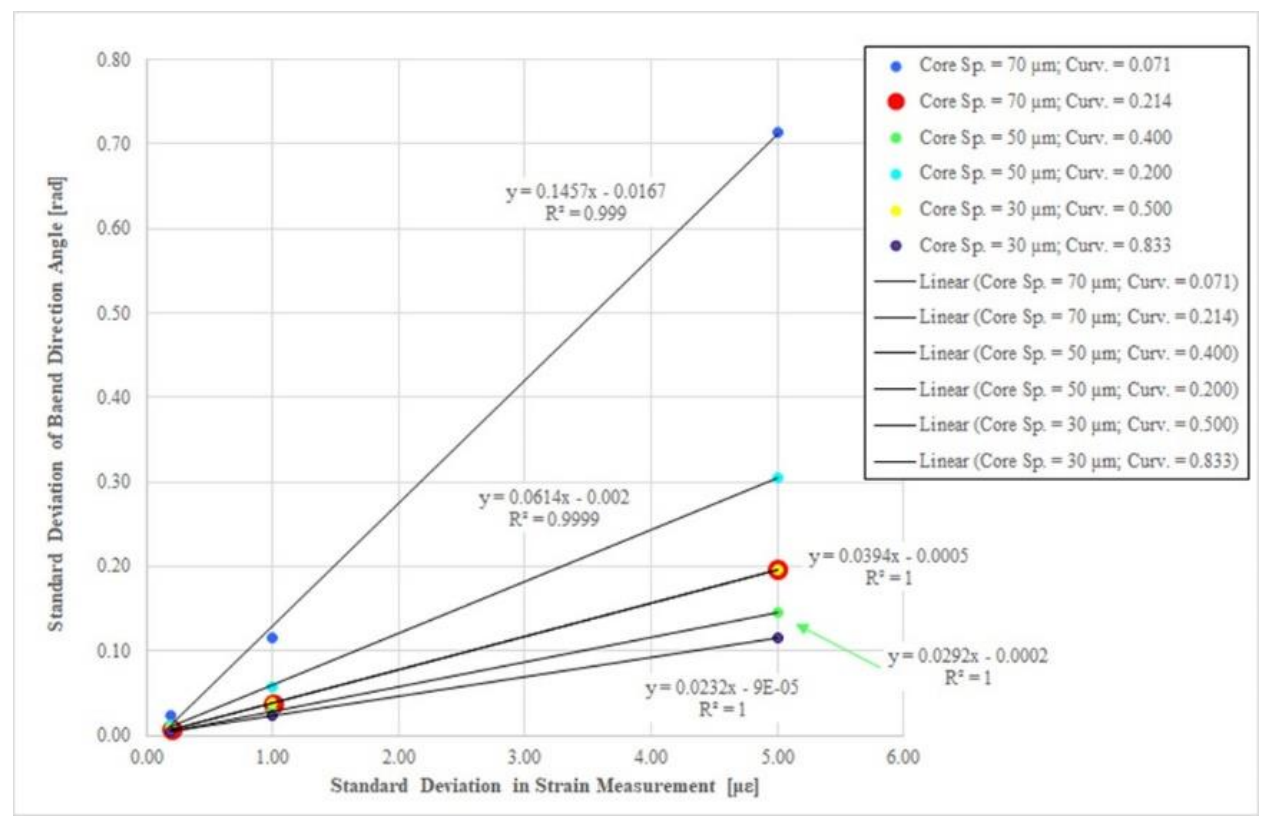

Fig. 13. Bending direction angle SD results for each strain SD data point at constant core spacing and curvature values. 
Considering that the precision of the bending axis estimation greatly depends on the curvature sensed, the variation of the bending direction angle SD was studied considering the ratio between strain SD and curvature at a fixed value of core spacing (see Fig. 14), and the ratio between core spacing and curvature at a fixed value of strain SD (see Fig. 15). In both cases, the relationships are linear. The regression line equations and coefficients of determination $\left(\mathrm{R}^{2}\right)$ are included in the figures.

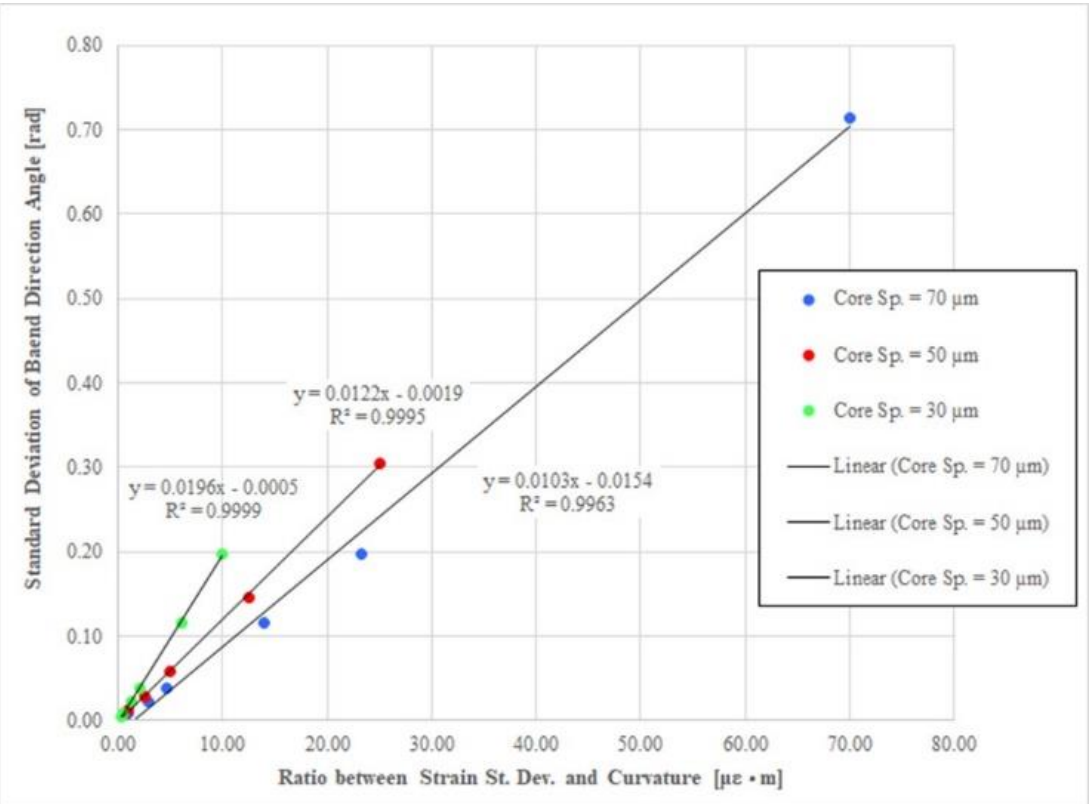

Fig. 14. Bending direction angle SD results for each strain SD and curvature ratio data point at constant core spacing values. 


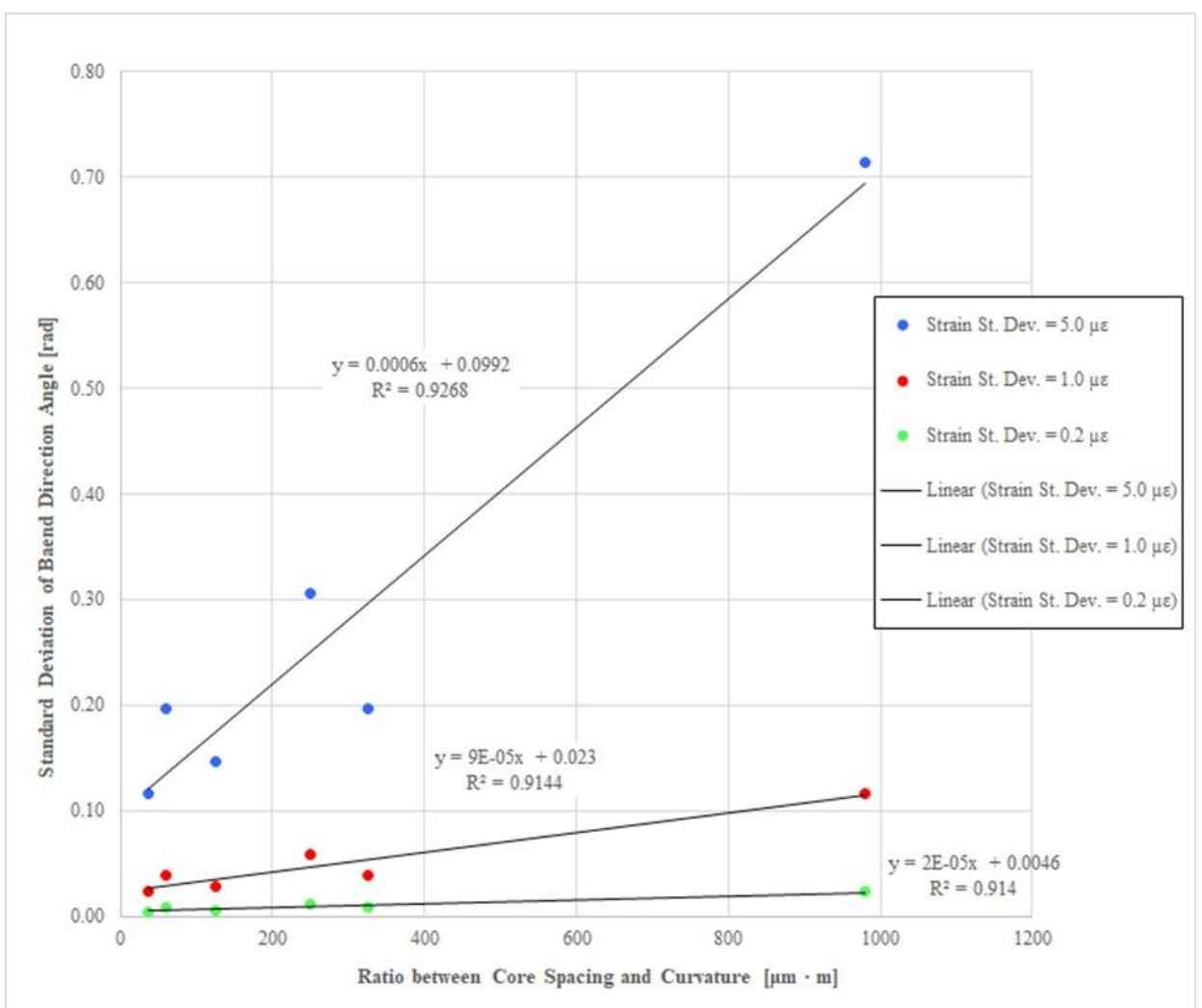

Fig. 15. Bending direction angle SD results for each core spacing and curvature ratio data point at constant strain SD values.

Here again a test of statistical significance was carried out to verify that the length of the sample records $\left(10^{6}\right)$ was statistically robust by comparing the results obtained with the subdatasets and the total dataset. In each simulation, the percentage errors of the subdatasets were compared with the total dataset by Eq. (5). The highest percentage error obtained was 0.361 , indicating that the simulation can be considered statistically significant. The results are shown in Tables 8 and 9. 
Table 8. Bending direction angle SD results; comparison of subdatasets and total dataset.

\begin{tabular}{c|c|c|c|c|c|c}
\hline $\begin{array}{c}\text { Simulation } \\
\text { number }\end{array}$ & $\begin{array}{c}\text { Bend. Dir. Angle } \\
\text { St. Dev. 1 } \\
\text { dataset }\end{array}$ & $\begin{array}{c}\text { Bend. Dir. } \\
\text { Angle St. Dev. } \\
2^{\circ} \text { dataset }\end{array}$ & $\begin{array}{c}\text { Bend. Dir. } \\
\text { Angle St. Dev. } \\
3^{\circ} \text { dataset }\end{array}$ & $\begin{array}{c}\text { Bend. Dir. } \\
\text { Angle St. Dev. } \\
4^{\circ} \text { dataset }\end{array}$ & $\begin{array}{c}\text { Bend. Dir. } \\
\text { Angle St. Dev. } \\
5^{\circ} \text { dataset }\end{array}$ & $\begin{array}{c}\text { Bend. Dir. } \\
\text { Angle St. Dev. } \\
\text { Total dataset }\end{array}$ \\
\hline 1 & 0.713099 & 0.712740 & 0.715035 & 0.715513 & 0.714393 & 0.714156 \\
2 & 0.196032 & 0.196060 & 0.196784 & 0.196507 & 0.196430 & 0.196362 \\
3 & 0.116487 & 0.116364 & 0.116278 & 0.116615 & 0.116200 & 0.116389 \\
4 & 0.038519 & 0.038558 & 0.038617 & 0.038453 & 0.038412 & 0.038512 \\
5 & 0.023031 & 0.023104 & 0.023050 & 0.023048 & 0.023108 & 0.023068 \\
6 & 0.007700 & 0.007719 & 0.007686 & 0.007700 & 0.007694 & 0.007700 \\
7 & 0.305244 & 0.304521 & 0.304990 & 0.305689 & 0.305210 & 0.305131 \\
8 & 0.145566 & 0.145794 & 0.146136 & 0.145968 & 0.145992 & 0.145891 \\
9 & 0.057893 & 0.058085 & 0.057790 & 0.057979 & 0.057782 & 0.057906 \\
10 & 0.028811 & 0.028781 & 0.028924 & 0.028826 & 0.028872 & 0.028843 \\
11 & 0.011516 & 0.011559 & 0.011524 & 0.011556 & 0.011581 & 0.011547 \\
12 & 0.005779 & 0.005780 & 0.005779 & 0.005762 & 0.005764 & 0.005773 \\
13 & 0.196357 & 0.196175 & 0.196551 & 0.196377 & 0.196933 & 0.196479 \\
14 & 0.116109 & 0.115894 & 0.116204 & 0.116303 & 0.116170 & 0.116136 \\
15 & 0.038444 & 0.038521 & 0.038628 & 0.038637 & 0.038483 & 0.038543 \\
16 & 0.023083 & 0.023074 & 0.023115 & 0.023104 & 0.023102 & 0.023096 \\
17 & 0.007700 & 0.007707 & 0.007666 & 0.007697 & 0.007700 & 0.007694 \\
\hline & 0.004613 & 0.004608 & 0.004622 & 0.004612 & 0.004605 & 0.004612 \\
\hline
\end{tabular}

Table 9. Bending direction angle SD results; percentage errors.

\begin{tabular}{c|c|c|c|c|c}
\hline $\begin{array}{c}\text { Simulation } \\
\mathrm{N}^{\circ}\end{array}$ & $\begin{array}{c}\text { Percentage } \\
\text { Error 1st } \\
\text { Dataset }\end{array}$ & $\begin{array}{c}\text { Percentage } \\
\text { Error 2nd } \\
\text { Dataset }\end{array}$ & $\begin{array}{c}\text { Percentage } \\
\text { Error 3rd } \\
\text { Dataset }\end{array}$ & $\begin{array}{c}\text { Percentage } \\
\text { Error 4th } \\
\text { Dataset }\end{array}$ & $\begin{array}{c}\text { Percentage } \\
\text { Error 5th } \\
\text { Dataset }\end{array}$ \\
\hline 1 & -0.148 & -0.198 & 0.123 & 0.190 & 0.033 \\
2 & -0.168 & -0.154 & 0.215 & 0.073 & 0.035 \\
3 & 0.084 & -0.021 & -0.095 & 0.194 & -0.162 \\
4 & 0.018 & 0.120 & 0.273 & -0.153 & -0.259 \\
5 & -0.161 & 0.154 & -0.077 & -0.088 & 0.173 \\
6 & 0.000 & 0.247 & -0.176 & 0.001 & -0.072 \\
7 & 0.037 & -0.200 & -0.046 & 0.183 & 0.026 \\
8 & -0.223 & -0.066 & 0.168 & 0.053 & 0.069 \\
9 & -0.021 & 0.309 & -0.200 & 0.126 & -0.213 \\
10 & -0.111 & -0.212 & 0.281 & -0.059 & 0.102 \\
11 & -0.274 & 0.104 & -0.204 & 0.078 & 0.294 \\
12 & 0.117 & 0.119 & 0.107 & -0.190 & -0.154 \\
13 & -0.062 & -0.154 & 0.037 & -0.052 & 0.231 \\
14 & -0.023 & -0.209 & 0.059 & 0.144 & 0.029
\end{tabular}




\begin{tabular}{l|c|c|c|c|c}
15 & -0.255 & -0.057 & 0.222 & 0.244 & -0.155 \\
16 & -0.053 & -0.095 & 0.085 & 0.036 & 0.026 \\
17 & 0.079 & 0.171 & -0.361 & 0.038 & 0.072 \\
18 & 0.019 & -0.084 & 0.213 & 0.004 & -0.153 \\
\hline
\end{tabular}

\section{Conclusions}

High precision in curvature and bending direction computation is fundamental for several applications in Structural Health Monitoring, such as continuous monitoring of the verticality of structures, including buildings, towers, bridge piles, tunnel displacement, etc. Curvature and bending direction are the inputs for shape sensing reconstruction, which can be used in a variety of medical, aerospace, mechanical, and civil engineering applications.

This study focused on the propagation of strain uncertainty in curvature and bending direction sensing, simulating the measurement process by the Monte Carlo method with $10^{6}$ iterations, considering the 7-core multicore fiber section with different core spacing, one of the most widely used fiber geometries in shape sensing applications.

A statistical significance test was carried out to verify the results of the experiment and determine the relation between strain uncertainty and core spacing variation and curvature and bending direction precision.

The following conclusions can be drawn from this study:

- MCM is an efficient method of studying the propagation of the strain measurement errors in calculating curvature and bending direction.

- The curvature distribution is greatly and non-linearly influenced by the core spacing and depends linearly on the strain SD.

- The SD of the distribution of the angle between bending direction and the axis $\mathrm{x}$ depends linearly on the core spacing and the measured strain SD. As it is also strongly dependent on the curvature sensed, the accuracy of the sensor is related to the application.

- The precision in determining curvature and bending direction depends largely on the core spacing. A highly sensitive shape sensor could be designed with larger core spacing fibers than those employed in telecommunications.

- The precision of bending direction and curvature detection can be calculated after determining the core spacing of the fiber, the strain measurement SD and the curvature sensed, using the charts in Figures 7-8 and 11-12.

The outcomes show the strong influence of strain uncertainty and core spacing on MCF sensor precision in sensing curvature and bending direction. The relations identified in this research project could be used to calculate the maximum performance achievable by 7-core MCF curvature sensors after finding the strain SD of the gratings and core spacing, while acknowledging that if further errors affect the phenomenon the precision will be lower than expected.

These results show that a different fiber geometry with larger core spacing could be produced by taking advantage of the remarkable improvement that can be obtained by slightly increasing the distance between the outer cores and the fiber axis. Furthermore, the proposed equations can be used to design sensors with the required accuracy for specific cases of determining curvature and bending direction. Lastly, these findings could be used as the starting point for investigating MCF sensor precision for shape and position sensing. 


\section{Acknowledgments}

This work was carried out within the ITN-FINESSE framework, funded by the European Union's Horizon 2020 Research and Innovation Program under the Marie Sklodowska-Curie Action Grant Agreement N 722509.

\section{References}

[1] D. Tosi, E. Schena, C. Molardi, S. Korganbayev, Fiber optic sensors for sub-centimeter spatially resolved measurements: Review and biomedical applications, Opt. Fiber Technol. 43 (2018) 6-19. doi:10.1016/j.yofte.2018.03.007.

[2] H.F. Pei, J. Teng, J.H. Yin, R. Chen, A review of previous studies on the applications of optical fiber sensors in geotechnical health monitoring, Meas. J. Int. Meas. Confed. 58 (2014) 207-214. doi:10.1016/j.measurement.2014.08.013.

[3] H.Z. Yang, X.G. Qiao, D. Luo, K.S. Lim, W. Chong, S.W. Harun, A review of recent developed and applications of plastic fiber optic displacement sensors, Meas. J. Int. Meas. Confed. 48 (2014) 333-345. doi:10.1016/j.measurement.2013.11.007

[4] R.M. Liu, D.K. Liang, A. Asundi, Small diameter fiber Bragg gratings and applications, Meas. J. Int. Meas. Confed. 46 (2013) 3440-3448. doi:10.1016/j.measurement.2013.05.016.

[5] A. Barrias, J. Casas, S. Villalba, A Review of Distributed Optical Fiber Sensors for Civil Engineering Applications, Sensors. 16 (2016) 748. doi:10.3390/s16050748.

[6] J. Villatoro, A. Van Newkirk, E. Antonio-Lopez, J. Zubia, A. Schülzgen, R. Amezcua-Correa, Ultrasensitive vector bending sensor based on multicore optical fiber., Opt. Lett. 41 (2016) 832-5. doi:10.1364/OL.41.000832.

[7] W.N. MacPherson, M. Silva-Lopez, J.S. Barton, a J. Moore, J.D.C. Jones, D. Zhao, L. Zhang, I. Bennion, N. Metje, D.N. Chapman, C.D.F. Rogers, Tunnel monitoring using multicore fibre displacement sensor, Meas. Sci. Technol. 17 (2006) 1180-1185. doi:10.1088/0957-0233/17/5/S41.

[8] A. Fender, W.N. MacPherson, R.R.J. Maier, J.S. Barton, D.S. George, R.I. Howden, G.W. Smith, B.J.S. Jones, S. McCulloch, X. Chen, R. Suo, L. Zhang, I. Bennion, Two-axis accelerometer based on multicore fibre Bragg gratings, IEEE Sens. J. 8 (2007) 66190Q-66190Q-4. doi:10.1117/12.738411.

[9] P.S. Westbrook, T. Kremp, K.S. Feder, W. Ko, E.M. Monberg, H. Wu, D.A. Simoff, T.F. Taunay, R.M. Ortiz, Continuous Multicore Optical Fiber Grating Arrays for Distributed Sensing Applications, J. Light. Technol. 35 (2017) 1248-1252. doi:10.1109/JLT.2017.2661680.

[10] E.M. Lally, M. Reaves, E. Horrell, S. Klute, M.E. Froggatt, Fiber optic shape sensing for monitoring of flexible structures, in: M. Tomizuka, C.-B. Yun, J.P. Lynch (Eds.), Proc. SPIE - Int. Soc. Opt. Eng., 2012: p. 83452Y. doi:10.1117/12.917490

[11] J. Salo, I. Korhonen, Calculated estimate of FBG sensor's suitability for beam vibration and strain measuring, Measurement. 47 (2014) 178-183. doi:10.1016/j.measurement.2013.08.017.

[12] M.J. Gander, W.N. MacPherson, R. McBride, J.D.C. Jones, L. Zhang, I. Bennion, P.M. Blanchard, J.G. Burnett, a H. Greenaway, Bend mesurement using Bragg gratings in multicore fibre, Electron. Lett. 36 (2000) 2-3.

[13] M.Z. Marković, J.S. Bajić, M. Vrtunski, T. Ninkov, D.D. Vasić, M.B. Živanov, Application of fiber-optic curvature sensor in deformation measurement process, Meas. J. Int. Meas. Confed. 92 (2016) 50-57. doi:10.1016/j.measurement.2016.06.001.

[14] D. Barrera, I. Gasulla, S. Sales, Multipoint Two-Dimensional Curvature Optical Fiber Sensor Based on a Nontwisted Homogeneous Four-Core Fiber, J. Light. Technol. 33 (2015) 2445-2450. doi:10.1109/JLT.2014.2366556.

[15] G.M.H. Flockhart, W.N. MacPherson, J.S. Barton, J.D.C. Jones, L. Zhang, I. Bennion, Two-axis bend measurement with Bragg gratings in multicore optical fiber, Opt. Lett. 28 (2003) 387. doi:10.1364/OL.28.000387. 
[16] W.N. MacPherson, G.M.H. Flockhart, R.R.J. Maier, J.S. Barton, J.D.C. Jones, D. Zhao, L. Zhang, I. Bennion, Pitch and roll sensing using fibre Bragg gratings in multicore fibre, Meas. Sci. Technol. 15 (2004) 1642-1646. doi:10.1088/0957-0233/15/8/036.

[17] J.P. Moore, M.D. Rogge, Shape sensing using multi-core fiber optic cable and parametric curve solutions, Opt. Express. 20 (2012) 2967. doi:10.1364/OE.20.002967.

[18] J. Langer, D. a. Singer, Lagrangian Aspects of the Kirchhoff Elastic Rod, SIAM Rev. 38 (1996) 605-618. doi:10.1137/S0036144593253290.

[19] https://www.fibercore.com/product/multicore-fiber, https://www.fibercore.com/product/multicore-fiber, (n.d.).

[20] P.S. Westbrook, K.S. Feder, T. Kremp, T.F. Taunay, E. Monberg, J. Kelliher, R. Ortiz, K. Bradley, K.S. Abedin, D. Au, G. Puc, Integrated optical fiber shape sensor modules based on twisted multicore fiber grating arrays, in: I. Gannot (Ed.), 2014: p. 89380H. doi:10.1117/12.2041775.

[21] L.J. Cooper, A.S. Webb, A. Gillooly, M. Hill, T. Read, P. Maton, J. Hankey, A. Bergonzo, Design and performance of multicore fiber optimized towards communications and sensing applications, in: S. Jiang, M.J.F. Digonnet (Eds.), Proc. SPIE - Int. Soc. Opt. Eng., 2015: p. 93590H. doi:10.1117/12.2076950.

[22] Z. Zhao, M.A. Soto, M. Tang, L. Thévenaz, Distributed shape sensing using Brillouin scattering in multi-core fibers, Opt. Express. 24 (2016) 25211. doi:10.1364/OE.24.025211.

[23] P.S. Westbrook, T. Kremp, K.S. Feder, W. Ko, E.M. Monberg, H. Wu, D.A. Simoff, S. Shenk, R.M. Ortiz, Performance characteristics of continuously grated multicore sensor fiber, in: Y. Chung, W. Jin, B. Lee, J. Canning, K. Nakamura, L. Yuan (Eds.), 2017: p. 103236I. doi:10.1117/12.2263481.

[24] V. Synek, Effect of insignificant bias and its uncertainty on the coverage probability of uncertainty intervalsPart 2. Evaluation for a found insignificant experimental bias, Talanta. 71 (2007) 1304-1311. doi:10.1016/j.talanta.2006.06.038.

[25] C.E. Papadopoulos, H. Yeung, Uncertainty estimation and Monte Carlo simulation method, Flow Meas. Instrum. 12 (2001) 291-298. doi:10.1016/S0955-5986(01)00015-2.

[26] K. Shahanaghi, P. Nakhjiri, A new optimized uncertainty evaluation applied to the Monte-Carlo simulation in platinum resistance thermometer calibration, Meas. J. Int. Meas. Confed. 43 (2010) 901-911. doi:10.1016/j.measurement.2010.03.008.

[27] A.M. Saviano, F.R. Lourenço, Measurement uncertainty estimation based on multiple regression analysis (MRA) and Monte Carlo (MC) simulations - Application to agar diffusion method, Measurement. 115 (2018) 269-278. doi:10.1016/j.measurement.2017.10.057.

[28] R.M. Lequin, Guide to the Expression of Uncertainty of Measurement: Point/Counterpoint, Clin. Chem. 50 (2004) 977-978. doi:10.1373/clinchem.2003.030528.

[29] International Organization for Standardization Geneva ISBN, JCGM 101:2008, Joint Committee For Guides In Metrology. Evaluation of measurement data - Supplement 1 to the "Guide to the expression of uncertainty in measurement" - Propagation of distributions using a Monte Carlo method, 2008.

[30] M. Gilman, A brief survey of stopping rules in Monte Carlo simulations, Second Conf. Appl. Simulations. (1968) 16-20.

[31] I.T. Dimov, S. McKee, Monte Carlo Methods for Applied Scientists, (2008) 1-9.

[32] U.S. MATLAB R2015a, The MathWorks, Inc., Natick, Massachusetts, MATLAB R2015a, The MathWorks, Inc., Natick, Massachusetts, United States, (n.d.). 